\title{
Microstructural Investigations of Igneous Rims on CB CAIs
}

\author{
JANGMI HAN ${ }^{1,2}$, LINDSAY P. KELLER ${ }^{2}$, ALEXANDER N. \\ KROT $^{3}$, AND KAZUHIDE NAGASHIMA ${ }^{3}$ \\ ${ }^{1}$ Lunar \& Planetary Institute, USRA, USA. han@lpi.usra.edu. \\ ${ }^{2}$ ARES, Code XI3, NASA Johnson Space Center, USA. \\ ${ }^{3}$ University of Hawai'i at Mānoa, USA.
}

Coarse-grained, igneous CAIs from CB3.0 chondrites are surrounded by igneous rim layers of \pm melilite, \pm diopside, and Ca-forsterite [1]. They are isotopically uniform, but ${ }^{16} \mathrm{O}-$ depleted relative to most CAIs from unmetamorphosed CR2, $\mathrm{CM}$ 2, and $\mathrm{CO} 3.0$ chondrites characterized by solar-like $\Delta^{17} \mathrm{O}$ $\sim-23 \pm 2 \%$ [2]. The CB CAI oxygen isotopic compositions are inferred to have resulted from gas-melt $\mathrm{O}$-isotope exchange in an impact-induced plume with $\Delta^{17} \mathrm{O}$ of $\sim-2 \%$ [2]. Here we present TEM results of igneous rims on two igneous CAIs from the CB chondrite Hammadah al Hamra 237 to provide better mineralogical, chemical, and textural constraints on their formation conditions.

Pyroxene-spinel-melilite-rich CAI $Y A-1$ with $\Delta^{17} \mathrm{O}$ of $-9 \pm 2 \%$ is rimmed by three distinct layers (from inside outward): Al-diopside (10-20 wt $\% \mathrm{Al}_{2} \mathrm{O}_{3}$ ), diopside (1 $\mathrm{wt} \%$ $\mathrm{Al}_{2} \mathrm{O}_{3}$ ), and Ca-forsterite. The diopside layer, $<0.5 \mu \mathrm{m}$ in thickness, is in a crystallographic continuity with the underlying Al-diopside. Forsterite contains $0.5 \mathrm{wt} \% \mathrm{CaO}$ and displays a fine-scale columnar morphology, with clusters of crystals sharing the same crystallographic orientation.

Hibonite-spinel-melilite-rich CAI $Y A-2$ with $\Delta^{17} \mathrm{O}$ of $-8 \pm 2 \%$ is rimmed by melilite with minor spinel and perovskite, Al,Ti-diopside (5-13 wt $\% \mathrm{TiO}_{2}$ and $20-23 \mathrm{wt} \%$ $\left.\mathrm{Al}_{2} \mathrm{O}_{3}\right)$, Al-diopside $\left(<10 \mathrm{wt} \% \mathrm{Al}_{2} \mathrm{O}_{3}\right)$, and finally low-Ca pyroxene $(2 \mathrm{wt} \% \mathrm{CaO})$. No forsterite is observed on the inclusion exterior. The melilite layer consists of micrometersized grains and shock-deformed assemblages of amorphous and nanometer-sized, crystalline grains. The outer diopside and pyroxene layers are compositionally distinct, but are in a crystallographic continuity relative to each other.

The observed microstructures of multi-layered rims on two CB CAIs suggest that the rim formation occurred under rapidly changing conditions [3], but with a strong crystallographic control. The presence of Ca-forsterite or lowCa pyroxene as the final rim layer likely reflects differences in the degree of $\mathrm{Mg}$ and $\mathrm{Si}$ saturation in an impact-induced plum gas, as well as bulk composition of proto-CAIs $[1,2]$.

References: [1] Krot A. N. et al. (2001) MAPS 36, 1189-1217. [2] Krot A. N. et al. (2017) GCA 201, 155-184. [3] Kobatake H. et al. (2008) Icarus 198, 208-217. 